\title{
Vitamin B-12 and folate deficiency presenting as leukaemia
}

\author{
I S Dokal, T M Cox, D A G Galton
}

Vitamin B-12 and folate deficiency may be mistaken for leukaemia, and caution should be taken if bone marrow cannot be aspirated or the morphology is atypical

\section{Department of \\ Haematology, Royal \\ Postgraduate Medical \\ School and Hammersmith \\ Hospital, London \\ W12 0NN \\ I S Dokal, MRCP, research fellow \\ T M Cox, FRCP, senior lecturer D A G Galton, FRCP, emeritus professor}

Correspondence to:

Dr Dokal.

BrMed f 1990;300:1263-4
The term leukaemoid reaction has been used to describe a peripheral blood leucocytosis that resembles leukaemia but occurs in a person who does not have leukaemia. ' Leukaemoid reactions occur as secondary phenomena and are most commonly associated with infections (especially miliary tuberculosis), although they also occur soon after birth in Down syndrome ${ }^{2}$ and have occasionally been reported in association with malignant disease. ${ }^{34}$ The monocytic, lymphocytic, or granulocytic cell lines may be affected, and differentiation between the reactive change and true leukaemia may under some circumstances be possible only after prolonged observation. We report on two patients, one with vitamin B-12 deficiency and one with severe folate deficiency, whose blood picture and bone marrow appearances closely resembled those found in leukaemia.

\section{Case reports}

CASE 1

In March 1987 a 43 year old woman presented with a three month history of weight loss, malaise, anorexia, and shortness of breath and a two day history of epistaxis. She was pale and had jaundice and a tachycardia with a systolic flow murmur; her liver was palpable $1 \mathrm{~cm}$ below the right costal margin.

Investigations showed a haemoglobin concentration of $31 \mathrm{~g} / \mathrm{l}$; a white cell count of $24.4 \times 10^{9} / 1$ (blasts $1 \%$, myelocytes $4 \%$, metamyelocytes $10 \%$, neutrophils $71 \%$, lymphocytes $11 \%$, monocytes $4 \%$; ratio of nucleated red cells to white cells $37: 100$ ); a platelet count of $80 \times 10^{\%} / 1$; and a reticulocyte count of $19 \cdot 2 \times 10^{9} / 1$. A blood film showed appreciable anisocytosis, poikilocytes, polychromasia, and hypersegmentation of neutrophils (mean corpuscular volume $89 \mathrm{fl}$ ) (fig 1). Bone marrow aspiration was unsuccessful, and a bone marrow trephine biopsy was therefore carried out. On the second day of admission she developed a chest infection, and antibiotic treatment was started.

While awaiting the results of the trephine biopsy she was given vitamin B-12 (1 mg immediately) and folate ( $5 \mathrm{mg}$ daily) was started because of the possibility of nutritional deficiency. The biopsy sections showed that the bone marrow was infiltrated by numerous

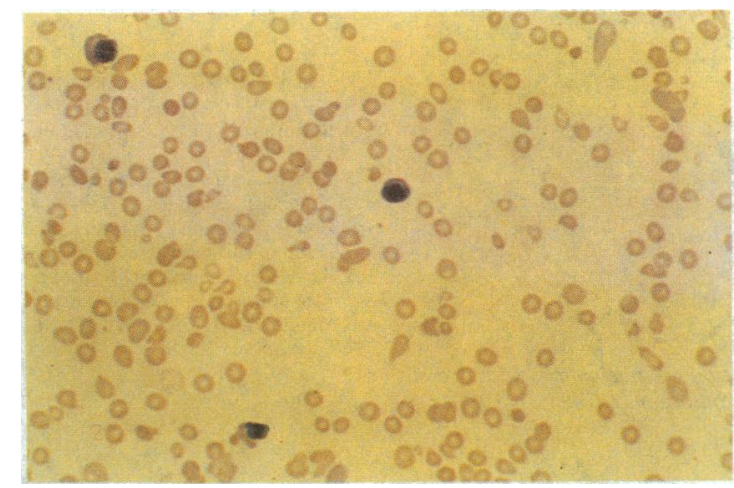

FIG 1-Peripheral blood film stained with haematoxylin and eosin showing anisocytosis, poikilocytes, polychromasia, and nucleated red cells (case 1)

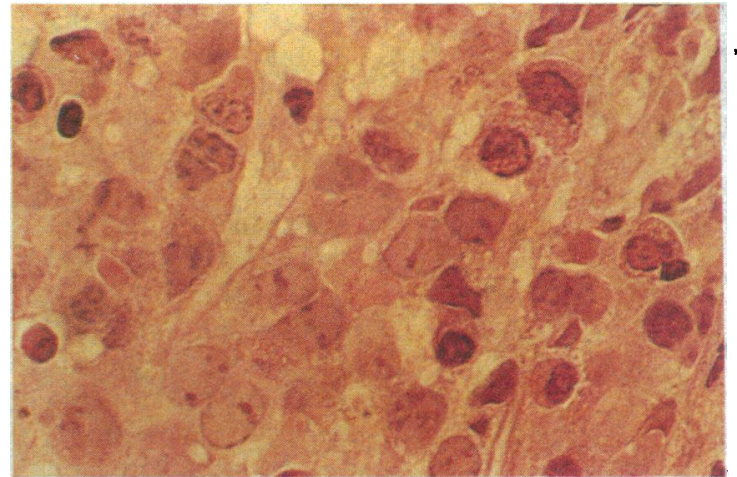

FIG 2-Bone marrow trephine biopsy stained with haematoxylin and eosin showing infiltration of bone marrow by numerous large, primitive blast cells (case 1)

large, primitive blast cells that were considered to be of granulocytic origin (fig 2). We made a preliminary diagnosis of acute leukaemia and arranged for a Hickman catheter to be inserted for cytotoxic chemotherapy. There were technical difficulties, however, and before chemotherapy was started the values for serum vitamin B-12 and folate concentrations became available. The vitamin B-12 concentration was $33.2 \mathrm{pmol} / \mathrm{l}$ (normal $125-683 \mathrm{pmol} / \mathrm{l}$ ) but the folate concentration was normal. Her peripheral blood count had improved considerably (haemoglobin concentration $91 \mathrm{~g} / 1$, white cell count $5 \cdot 0 \times 10^{9} / 1$, platelets $\left.90 \times 10^{9} / 1\right)$, in association with a moderate reticulocyte response (maximum $220 \times 10^{\%} / 1$ ). The bone marrow was re-examined two weeks after vitamin B-12 was given, and the aspirate showed only a few blasts in an otherwise normal bone marrow.

We concluded that the features of the peripheral blood and marrow that had been mistaken for a form of acute myeloid leukaemia were the result of vitamin B-12 deficiency. The Schilling test (part 1 and part 2) and a screen for gastric parietal cell antibodies indicated that the deficiency was caused by pernicious anaemia. In May 1989 the patient was well and had a normal peripheral cell count and blood film (haemoglobin concentration $127 \mathrm{~g} / 1$, white cell count $6 \cdot 1 \times 10^{9} / 1$, platelet count $\left.302 \times 10^{9} / 1\right)$.

CASE 2

In April 1972, a 52 year old woman presented with a two week history of upper respiratory tract infection, stomatitis, glossitis, diarrhoea, and excess flatus. She subsequently developed menorrhagia, spontaneous bruising, and haematemesis. She was pale and feverish and had toxic confusion. Purpura, severe stomatitis, pharyngeal erythema, and palatal petechiae were also visible. The edge of her liver could be felt $2 \mathrm{~cm}$ below the costal margin, but the spleen was not palpable; there was gaseous distension of the abdomen with high pitched bowel sounds. A neurological examination gave normal results.

Her peripheral cell count showed a haemoglobin concentration of $53 \mathrm{~g} / \mathrm{l}$, a white cell count of $1 \cdot 2 \times 10^{9} / \mathrm{l}$ (blasts $2 \%$, promyelocytes $2 \%$, myelocytes $2 \%$, neutrophils $15 \%$, lymphocytes $78 \%$ ), a platelet count of $40 \times 10^{9} / 1$, a reticulocyte count of $4 \cdot 5 \times 10^{9} / 1$. A blood film showed anisocytosis, poikilocytes, and macrocytes 
(mean corpuscular volume $99 \mathrm{f}$ ). The myelocytes had abnormally heavy granulation, and there were large, trilobed neutrophils with prominent vacuoles in the cytoplasm and nuclei. A few myeloblasts were present, and their appearance suggested acute promyelocytic leukaemia (fig 3). This diagnosis was supported by films of aspirated bone marrow, which showed a ratio of myeloid to erythroid cells of $8: 1$, and arrested maturation of granulocyte precursors at the promyelocytic stage (fig 4). Erythropoiesis was depressed, and megaloblasts were present.

We found later that her serum folic acid concentration was very low $(0 \cdot 23 \mathrm{nmol} / \mathrm{l}$ (normal $4 \cdot 5-22 \cdot 6$ $\mathrm{nmol} / \mathrm{l})$ ), but her serum vitamin B-12 concentration was normal $(295 \mathrm{pmol} / \mathrm{l})$. We therefore concluded that she had megaloblastic anaemia due to folic acid deficiency with arrested maturation of granulocytes, which had resulted in an excess of promyelocytes in the bone marrow. She responded well to parenteral folic acid treatment, and her peripheral blood and bone marrow rapidly returned to normal. Two weeks after she started treatment her haemoglobin concentration had risen to $110 \mathrm{~g} / \mathrm{l}$, and her reticulocyte count peaked at $600 \times 10^{9} / 1$ on day 16 .

Further investigations showed evidence for dietary deficiency of folate: (she had been consuming only $22 \mu \mathrm{g} /$ day; the minimum recommended dietary consumption is $100 \mu \mathrm{g} / \mathrm{day})$. The deficiency may have been exacerbated by her upper respiratory tract infection. We found no evidence for malabsorption of folate (the appearance of the jejunum in biopsy sections was normal) or any other underlying disorder such as occult malignancy. In January 1989, 17 years after her initial presentation, she was well and had a normal peripheral cell count and film (haemoglobin concentration $146 \mathrm{~g} / \mathrm{l}$, white cell count $7 \cdot 1 \times 10^{9} / 1$, platelet count $\left.380 \times 10^{9} / 1\right)$.

\section{Discussion}

Although we have heard anecdotally of cases in which vitamin B-12 or folate deficiency caused difficulty in diagnosis, we are not aware of any clear descriptions of patients who presented with leukaemoid reactions as a result. Barry and Salmon reported on a patient who presented with blood and bone marrow features that suggested a lymphocytic leukaemoid reaction. ${ }^{\text {s }}$ The patient, however, responded poorly to administration of vitamin B-12 but had a dramatic response to treatment with chlorambucil, suggesting that this was a true leukaemic process rather than a leukaemoid reaction.

Vitamin B-12 and folate are necessary for DNA

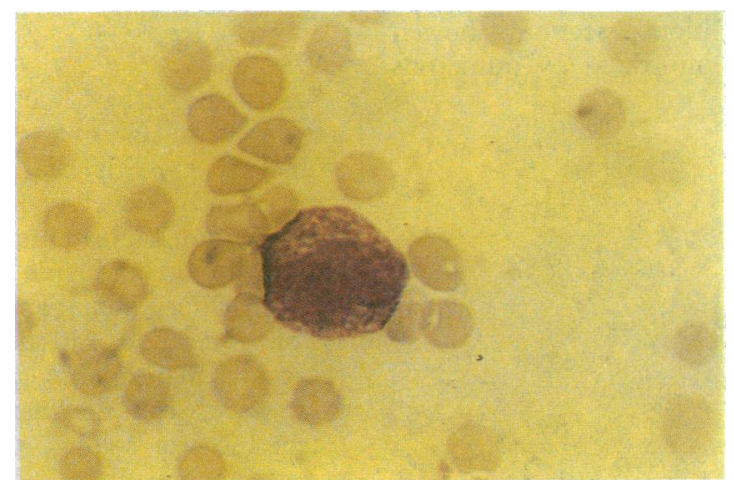

FIG 4-Bone marrow aspirate stained with haemotoxylin and eosin showing promyelocytes with heavy granulation (case 2)

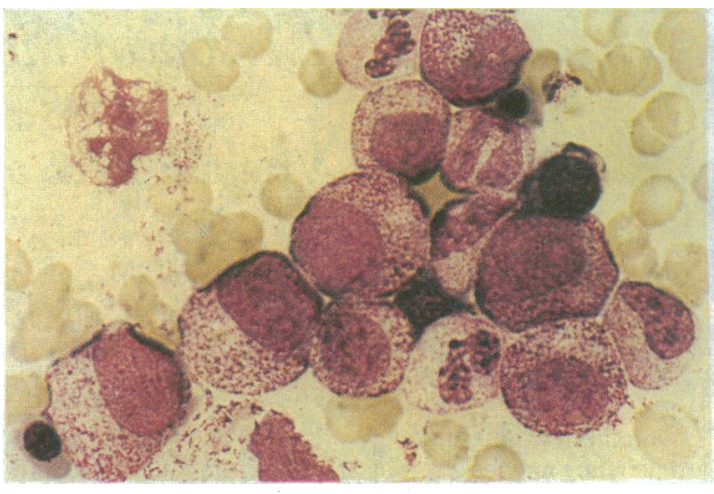

FIG 3-Peripheral blood film stained with haematoxylin and eosin showing a myelocyte with heavy granulation (case 2)

synthesis and normal cell division in the bone marrow. A deficiency of these vitamins causes megaloblastic anaemia as well as cytological changes in epithelia. In practice, there is usually a delay in obtaining serum vitamin B-12 and folate measurements, and megaloblastic anaemia is usually diagnosed by identifying megaloblastic changes in a bone marrow aspirate. ${ }^{6}$ In the cases described here, however, the haematological findings were not typical and the bone marrow changes, in particular, suggested acute myeloid leukaemia rather than megaloblastic anaemia.

The reason for such a variation in morphological appearances in these women is not clear. The woman in case 1 developed a chest infection on the second day of admission and the other woman had suffered an upper respiratory tract infection. The coexistence of megaloblastic anaemia and infection may have contributed to the unusual morphological features. In case 1 electrophoresis showed that the woman had haemoglobin $\mathrm{AC}$, and the other patient had coexisting iron deficiency. It is unlikely that haemoglobin $C$ could have influenced the leucocyte morphology, but iron deficiency may have complicated the haematological picture.

The first patient was nearly given cytotoxic treatment. We believe, in the light of this experience, that when bone marrow cannot be aspirated or when the morphology is not typical of leukaemia daily reticulocyte counts and careful monitoring of peripheral blood films would provide invaluable information. In such cases it may be preferable to defer treatment for leukaemia until the vitamin B-12 and serum folate concentrations are available or a more definitive blood picture emerges. This policy is unlikely to affect patients' outcome adversely if they have leukaemia and may prevent occasional patients with nutritional deficiency and possible infection receiving cytotoxic drugs inappropriately.

We thank Drs A Rahemtulla and P Ganly for their help in managing the patient in case 1 .

1 Krumbhaar EB. Leukemoid blood pictures in various clinical conditions. Am F Med Sci 1926;172:519-33.

2 Butturini A, Gale RP. Age of onset and type of leukaemia. Lancet 1989;ii: 789-91.

3 Bichel J. Lymphatic leukemia and lymphatic leukemoid states in cancer of the stomach. Blood 1949;4:759-66.

4 Lisa JR, Solomon C, Gordon EJ. Leukemoid reaction in carcinomatous skeletal and splenic metastases. American fournal of Cancer 1940;40:227-30.

5 Barry RE, Salmon PR. Recurrent leukaemoid reaction in pernicious anaemi complicated by gastric carcinoma. $\mathrm{BrMed} \mathcal{J}$ 1969;ii:612-3.

6 Mollin DL, Hoffbrand AV. The diagnosis of folate deficiency. Series Haematologica 1965;3:1-18.

(Accepted 27 November 1989) 